Pediat. Res. 3: 590-596 (1969)

Chain elongation fatty acid synthesis maturation myelination myelin synthesis rat brain

\title{
Fatty Acid Synthesis in the Developing Brain
}

\author{
Ernesto Aeberhard, Jorge Grippo, and John H. Menkes ${ }^{[27]}$ \\ Division of Pediatric Neurology, UCLA School of Medicine, Los Angeles, California, USA
}

\begin{abstract}
Extract
Fatty acid biosynthesis in the developing rat brain was studied. During development, total fatty acid synthesis was maximal at 15-16 days of age-a time of rapid myelination for this species. Results were expressed as $\mathrm{m} \mu$ moles of ${ }^{14} \mathrm{C}$-labeled acetyl-CoA incorporated into fatty acids per milligram of brain mitochondrial or microsomal protein, and as ${ }^{14} \mathrm{C}$-labeled malonyl-CoA incorporated per milligram of microsomal protein.

Elongation of saturated fatty acids by microsomes followed a similar developmental pattern. The peak incorporation of malonyl-CoA into saturated fatty acids occurred at 15 days of age, while synthesis of polyunsaturated fatty acid did not change significantly with maturation. In the mitochondrial-acetyl-CoA system, elongation of polyunsaturated fatty acids was also greatest at 15 days of age, while synthesis of saturated and monounsaturated fatty acids was unchanged significantly with maturation. These results support the concept that chain elongation of fatty acids is directly related to myelination. The marked increase in the rate of elongation of saturated fatty acid by the microsomal fraction, occurring at this time, suggests that this system is involved in synthesis of myelin fatty acids.
\end{abstract}

\section{Speculation}

At the time of myelination there is an increase in the activity of microsomes with respect to incorporating malonyl-CoA into saturated fatty acids, and into polyunsaturated fatty acids $(20: 2$ and $20: 4)$. This is unexpected because of the well established finding that in mature liver the microsomal fraction preferentially synthesizes polyunsaturated fatty acids, while the mitochondrial fraction forms saturated fatty acids. Polyunsaturated fatty acids constitute a relatively minor proportion of myelin fatty acids, and it is unlikely that the striking increase in microsomal activity observed at 15-16 days is necessary for their formation. It is possible that maturation changes the selectivity of the fatty acid synthesizing system, or that there are specificity differences between the hepatic and cerebral microsomal chain elongation systems.

\section{Introduction}

Biosynthesis of long-chain fatty acids proceeds by two mechanisms [19] - a de novo process that leads primarily to the formation of palmitic acid [20] $\left(\mathrm{C}_{16: 0}\right)$ and a chain elongation process involving the successive additions of acetate units to the primary fatty acid, of which palmitic acid is an example [7].
In an in vitro study of the biosynthesis of long-chain fatty acids by subcellular particles of mature rat brain, mitochondria and microsomes were found to incorporate acetyl-CoA and malonyl-CoA in the formation of a variety of saturated and unsaturated fatty acids by a chain elongation mechanism [1]. ATP and a reduced pyridine nucleotide were required for this process. Malonyl-CoA was found to be the active precursor 
for fatty acid biosynthesis in the microsomal elongation system, while both malonyl-CoA and acetyl-CoA were active precursors in the mitochondrial system. Even though the particulate fraction of the brain contained a de novo synthetic system, this did not appear to represent, normally, a major metabolic route. A significant amount of the newly synthesized fatty acids was incorporated into phospholipids, triglycerides, cholesterol, and cholesterol esters. Myelin, prepared by ultracentrifugation, was almost completely inactive with respect to fatty acid synthesis in vitro.

The present report describes fatty acid biosynthesis by subcellular particles in the developing rat brain.

\section{Materials}

Acetyl-1-14 C-CoA and malonyl-1,3-14 C-CoA [21] and the cofactors ATP, NADH, NADPH, creatine phosphate and creatine phosphokinase [22] were obtained from commercial sources. Lipids and fatty acid standards were obtained from another laboratory [23], and Cab-O-Sil [24], PPO [24], and POPOP [24] were obtained commercially.

\section{Methods}

Three or four immature rats of the Sprague-Dawley strain, age 4-30 days, and mature animals, age 3-10 months, were used in each experiment. Littermates for each age group were decapitated; brains were removed immediately and placed in a chilled sucrose solution. All subsequent procedures were carried out at a temperature of about $4^{\circ}$. Cerebral hemispheres were blotted on filter paper to remove blood and excess water and weighed; then they were homogenized with 9 volumes of ice-cold $0.32 \mathrm{M}$ sucrose in a glass homogenizer fitted with a Teflon pestle ( $0.12 \mathrm{~mm}$ clearance). The total homogenate was centrifuged at $1,000 \times g$ for $10 \mathrm{~min}$ to remove nuclei and cellular debris. The supernatant was the source for all fractions used in this study. A crude mitochondrial fraction was separated by differential centrifugation at $12,000 \times g$ for $30 \mathrm{~min}$. This was then fractionated into myelin, nerve ending, and purified mitochondrial subfractions by centrifugation at $50,000 \times g$ for $2 \mathrm{~h}$ into a discontinuous density gradient consisting of $0.8 \mathrm{M}$ and $1.2 \mathrm{M}$ sucrose in the $\mathrm{SW}$ 25 head of the Spinco model L preparative ultracentrifuge [10].

The microsomal fraction was prepared by centrifuging the $12,000 \times g$ supernatant at $50,000 \times g$ for $2 \mathrm{~h}$. Part of the supernatant from the last centrifugation was saved for study. Each fraction was washed twice with $0.32 \mathrm{M}$ sucrose and suspended in this solution.
The fractions obtained were characterized by activity of succinic and isocitric dehydrogenase and by electron-microscopic examination [1]. Protein in all fractions was determined using essentially the biuret method described by GoRnaLl et al. [9] with bovine serum albumin as a standard. In addition to the biuret reagent, sodium cholate was used to a final concentration of $0.26 \%$ to ensure optical clarity.

\section{Incubation Mixture}

The reaction mixture, unless specifically identified, contained $100 \mathrm{~m} \mu$ moles of acetyl-1 ${ }^{14} \mathrm{C}-\mathrm{CoA}(8.5 \mathrm{mCi} /$ $\mu$ mole) or $90 \mathrm{~m} \mu$ moles of malonyl-1,3-14 $\mathrm{C}$-CoA (9.4 $\mathrm{mCi} / \mu$ mole), $16 \mu$ moles of ATP, $3 \mu$ moles of NADPH, $3 \mu$ moles of $\mathrm{NADH}, 20 \mu$ moles of creatine phosphate, $0.25 \mathrm{mg}$ of creatine phosphokinase, $10 \mu$ moles of $\mathrm{MgCl}_{2}$, $60-100 \mu$ moles of potassium phosphate buffer ( $\mathrm{pH} 7.2)$, and $2.0-4.5 \mathrm{mg}$ of mitochondrial or microsomal protein in a final volume of $1.0 \mathrm{ml}$. The average protein content used in the incubation mixtures was $2.3 \mathrm{mg}$ for the mitochondrial fraction and $3.3 \mathrm{mg}$ for the microsomal fraction. The tubes were gently flushed with nitrogen, stoppered, and incubated at $38^{\circ}$. Initial experiments indicated that incorporation of substrate into fatty acids was linear for about $30 \mathrm{~min}$, then decreased to $58 \%$ linearity by $1 \mathrm{~h}$. A linear increase in fatty acid synthesis was also found at a concentration as high as $7.0 \mathrm{mg}$ microsomal protein $/ \mathrm{ml}$.

Determination of Incorporation of Radioactivity into Fatty Acids Following incubation periods of $30 \mathrm{~min}$ and $1 \mathrm{~h}$, the reaction mixture was saponified for $1 \mathrm{~h}$ at $95^{\circ}$ under nitrogen, with an equal volume of $20 \%$ methanolic $\mathrm{KOH}$. The nonsaponifiable compounds were extracted twice with hexane, and the aqueous phase was acidified with $4 \mathrm{~N} \mathrm{HCl}$; the fatty acids liberated were then extracted with three successive portions of hexane. The nonsaponifiable material was almost completely nonradioactive (1-3\% of total counts).

The combined extracts were concentrated to a known volume under a stream of nitrogen. An aliquot was transferred to a counting vial and dried under nitrogen; $15 \mathrm{ml}$ of a scintillation mixture consisting of $0.5 \%$ of 2,5-diphenyloxazole (PPO) and $0.005 \% 1,4-$ bis [2-(5-phenyloxazolyl)]-benzene (POPOP) in toluene were added. Radioactivity was counted in a Packard Tri-Carb liquid scintillation spectrometer. Results were reported as m $\mu$ moles of ${ }^{14} \mathrm{C}$-labeled substrate incorporated into fatty acids per milligram of protein in incubation mixture.

\section{Extraction and Separation of Lipids}

The total lipids from the reaction mixture were extracted with 20 volumes of chloroform-methanol $(2: 1, v / v)[5]$. The crude lipid extract was filtered and 
washed with 0.2 volume of water. The upper phase was removed, and the chloroform-rich, lower phase was washed three times with Folch's theoretical upper phase. In a parallel extraction procedure, in which acetyl-1-14C-CoA was added to a nonradioactive reaction mixture, contamination of the lower phase after the third washing amounted to less than $0.1 \%$ of the ${ }^{14} \mathrm{C}$ added.

The lower phase, which contained the lipids, was reduced to a small volume under nitrogen and then fractionated into lipid classes by thin-layer chromatography on silica gel $G$ [2]. A portion of the fatty acid methyl esters was separated into saturated, monounsaturated, and polyunsaturated fatty acids by thinlayer chromatography on silica gel $\mathrm{G}$ impregnated by silver nitrate $(5 \% \mathrm{w} / \mathrm{v})$ [14]. Identification was made by reference to standards run at the same time. Lipids were located by a brief exposure to iodine vapors, and the areas corresponding to each lipid were scraped from the plate and placed into counting vials with $15 \mathrm{ml}$ of scintillation mixture $(0.5 \% \mathrm{PPO}$ and $0.03 \%$ POPOP). Six-tenths of a gram of Cab-O-Sil [17], together with 1 or 2 drops of acetic acid, was added to each vial, and radioactivity was counted. From 95 to $98 \%$ of the radioactivity applicable to the thin-layer plate was recovered by this procedure.

Gal-liquid Chromatography and Identification of Fatty Acids

The hexane extract of radioactive fatty acids synthesized was dried under a stream of nitrogen. Fatty acid methyl esters were prepared by heating at $100^{\circ}$ for 2 min with $14 \%$ boron trifluoride in methanol [15] and purified by thin-layer chromatography. Gasliquid chromatography was carried out in a BarberColman model 10 gas chromatograph with an argon detector. Diethylene glycol succinate on Gas-Chrom Z [23], 100 to 120 mesh, and methyl silicone (SE-30) were used as stationary phases.

Peaks were identified by chromatography, with mixtures of standard fatty acid methyl esters. When standards were unavailable, peaks were given a tentative identity by a semilogarithmic plot of relative retention times.

The area under each peak was calculated by multiplying the peak height by the width at half-height; the percentage of a component was calculated from the ratio of the area of its peak to the total area for all eluted peaks. Quantitative results, using standards of the National Institutes of Health, agreed with the stated composition data, with a relative error of less than $10 \%$ for major components and an error of less than $1 \%$ in the absolute value of minor peaks.

The entire fractions were hydrogenated for $3 \mathrm{~h}$ with a platinum oxide catalyst and rechromatographed. Radioactive fatty acid methyl esters were collected from the gas chromatograph by means of a glass $\mathrm{U}$ tube, $4 \mathrm{~mm}$ in diameter, directly connected to the heated outlet. The bent portion of the tube was cooled by immersion in dry ice. The fatty acid esters were rinsed with $15 \mathrm{ml}$ of a scintillation mixture from the collection tubes into vials; the radioactivity was then measured. Approximately $70 \%$ of the radioactivity injected into the column was recovered.

\section{Decarboxylation of Fatty Acids}

Hexane extracts of the incubation mixtures and some individual fractions collected from the gas chromatograph were decarboxylated using the modified procedure [8] for the Schmidt reaction described by BRADY et al. [3]. Prior to decarboxylation, ethyl esters collected by gas-liquid chromatography were hydrolyzed by heating overnight with ethanolic $\mathrm{KOH}$ at $85^{\circ}$ [11]. This method yielded $82 \%$ of the radioactivity as ${ }^{14} \mathrm{CO}_{2}$ from a sample of uniformly ${ }^{14} \mathrm{C}$ labeled stearic acid.

\section{Results}

In vitro Incorporation of ${ }^{14} C$-labeled Substrate into FattyAcids by Rat Brain Mitochondria and Microsomes During Development Incorporation of acetyl- $1^{14} \mathrm{C}-\mathrm{Co} A$ into fatty acids. The relative specific activity of microsomal and mitochondrial fractions at various ages is shown in figure 1 . Similar to activity in adult brain, the mitochondrial fraction was several times more active than the microsomal fraction. For both systems, total fatty acid synthesis was maximal at 15-16 days of age. Thereafter, values declined to adult levels of one-half to one-third maximal.

Incorporation of malonyl-1,3-14 C-CoA into fatty acids by microsomal fraction. With malonyl-CoA as substrate, fatty acid synthesis by the microsomal fraction was maximal at 15 days of age. At that time, synthesis proceeded at about three times the rate of that found in mature brain and at twice the rate of synthesis characteristic of the mitochondrial system (fig. 2). Fatty acid synthesis was reported as millimicromoles of substrate incorporation per milligram of microsomal protein after incubation of 30 and $60 \mathrm{~min}$.

\section{Pattern of Fatty Acids Synthesized During Development}

As already noted for various tissues including brain, different products of fatty acid synthesis were obtained from the two particulate fractions used in this experiment (table I). The mitochondrial fraction incorporated acetyl-CoA into a variety of saturated, monounsaturated, and polyunsaturated fatty acids, with polyunsaturated fatty acids having the highest specific activity. 
Malonyl-CoA added to the microsomal fraction was preferentially converted into saturated fatty acids, with peak precursor incorporation occurring at 15 days of age. Of the major fatty acids, those of 20-carbon chain length $\left(\mathrm{C}_{20: 2}\right.$, and $\left.\mathrm{G}_{20: 4}\right)$ had the highest relative specific activity (table II) and accounted for $17.0 \%$ of radioactivity present in all fatty acids. This value contrasts with the microsomal system of adult brain

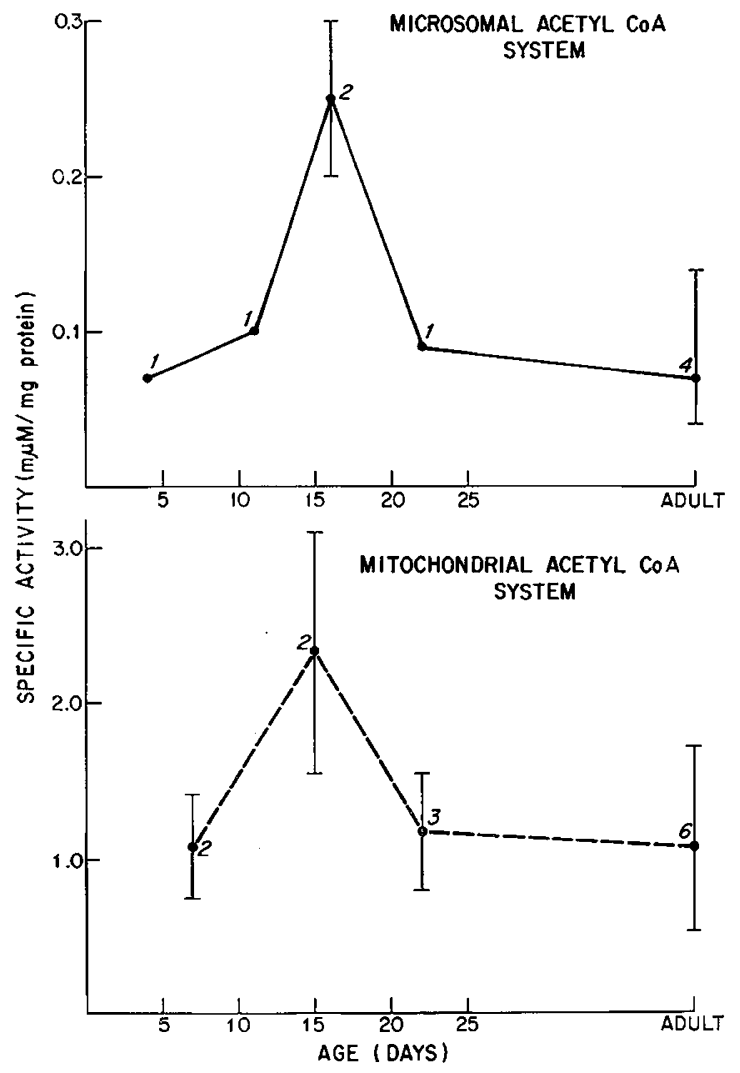

Fig. 1. In vitro incorporation of ${ }^{14} \mathrm{C}$-labeled acetyl-CoA into total fatty acids by rat brain microsomes and mitochondria during development. The results are expressed in terms of $m \mu$ moles of ${ }^{14} \mathrm{C}$-labeled substrate incorporated into fatty acids per $\mathrm{mg}$ of protein in the incubation mixture. The complete system contained $100 \mathrm{~m} \mu$ moles of aretyl-1 $-{ }^{14} \mathrm{C}-\mathrm{CoA}(58.5 \mathrm{mCi} / \mu \mathrm{mole})$, 16 m $\mu$ moles of ATP, $3 \mu$ moles of NADPH, $3 \mu$ moles of NADH, $20 \mu$ moles of creatinephosphate, $0.25 \mathrm{mg}$ of creatine phosphokinase, $10 \mu$ moles of $\mathrm{MgCl}_{2}$, and 60 $\mu$ moles of potassium phosphate buffer $(\mathrm{pH} 7.2)$ in a final volume of $1.0 \mathrm{ml}$. The reaction mixture was incubated for $30 \mathrm{~min}$ at $38^{\circ}$. Brackets indicate range of values, and the number under each figure indicates the number of experiments. which only incorporated $1.4 \%$ of radioactivity into these fatty acids [1]. Synthesis of polyunsaturated fatty acids occurred more rapidly than that of saturated fatty acids. When incubation was terminated after $10 \mathrm{~min}$, incorporation into polyunsaturated fatty acids was greater than incorporation into saturated fatty acids, and $\mathrm{C}_{22: 6}$ and $\mathrm{C}_{22: 4}$ fatty acids had the highest relative specific activity. As much as $40 \%$ of the radioactivity was found in a fraction which, when subjected to gas-liquid chromatography using diethylene glycol succinate as the stationary phase, had a retention time approximately equal to that of nervonic acid $\left(\mathrm{C}_{24: 1}\right)$. This fraction, however, accounted for less than $1 \%$ of the total fatty acids by weight, and the nature of the fraction is still unknown.

\section{Discussion}

In vivo studies of glycolipid metabolism [12] have shown that very young rats produce more $\mathrm{G}_{18: 0}$ cerebrosides than $\mathrm{C}_{24: 0}$ cerebrosides. This finding is consistent with studies on the fatty acid composition of sphingolipids in mature and immature human brain $[13,16,18]$. Prior to myelination, sphingolipids contain principally $\mathrm{G}_{16: 0}, \mathrm{G}_{18: 0}$, and $\mathrm{C}_{18: 1}$ fatty acids.

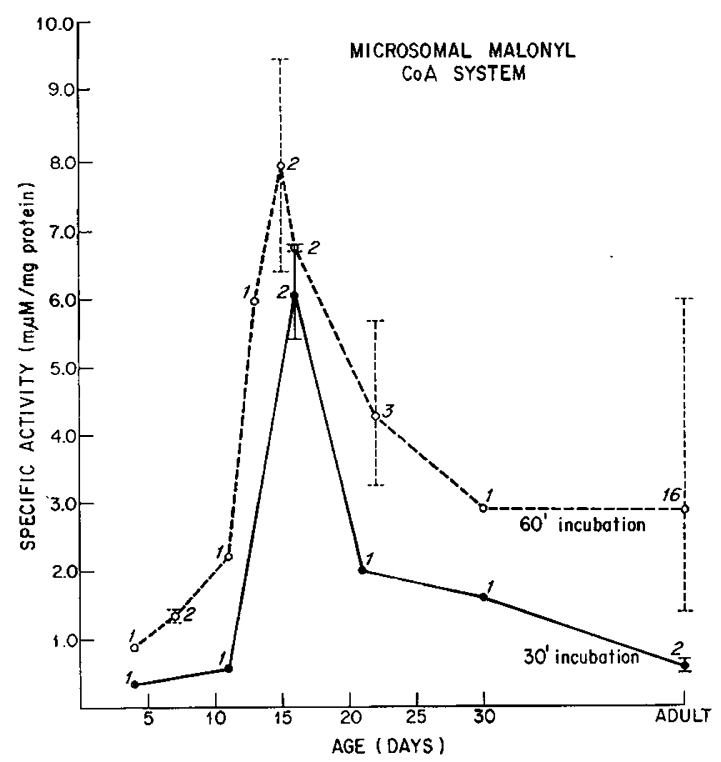

Fig. 2. In vitro incorporation of ${ }^{14} \mathrm{C}$-labeled malonyl-CoA into total fatty acids by rat brain microsomes during development. The results are expressed in terms of m $\mu$ moles of ${ }^{14} \mathrm{C}$-labeled precursor incorporated into fatty acids per $\mathrm{mg}$ of protein in the incubation mixture, after 30 and 60 min incubation. The complete system contained the components as described under figure 1 . 
A second type of sphingolipid that consists mainly of the very long-chain fatty acids, principally $\mathrm{C}_{24: 0}$ and $\mathrm{C}_{24: 1}$, and of $\alpha$-hydroxy fatty acids appears with myelination. While fatty acids of 16 and 18 carbon chain lengths can be produced by de novo synthesis, the very long-chain fatty acids can arise only through chain elongation.
Our studies of fatty acid biosynthesis in the developing rat brain support the concept that there is a close time relation between maximal fatty acid synthesis, particularly the elongation of saturated fatty acids by the microsomal malonyl-CoA system, and the period of rapid myelination. While synthesis of saturated fatty acids by the microsomal system was maximal at

Table I. Incorporation of acetyl-1-14 $\mathrm{C}-\mathrm{CoA}$ and malonyl-1,3-14 $\mathrm{C}-\mathrm{CoA}$ into fatty acids by rat brain mitochondria and microsomes ${ }^{1}$

\begin{tabular}{|c|c|c|c|c|c|c|c|}
\hline \multirow{3}{*}{$\begin{array}{l}\text { Age, } \\
\text { days }\end{array}$} & \multirow{3}{*}{ No. ${ }^{2}$} & \multicolumn{3}{|c|}{$\begin{array}{c}\text { Mitochondrial system } \\
\text { acetyl-CoA }\end{array}$} & \multirow{3}{*}{$\mathrm{No}^{2}$} & \multicolumn{2}{|c|}{$\begin{array}{l}\text { Microsomal system } \\
\text { malonyl-CoA }\end{array}$} \\
\hline & & $\begin{array}{l}\text { Saturated } \\
\text { fatty acids }\end{array}$ & $\begin{array}{c}\text { Poly- } \\
\text { unsaturated } \\
\text { fatty acids }\end{array}$ & $\begin{array}{c}\text { Mono- } \\
\text { unsaturated } \\
\text { fatty acids }\end{array}$ & & $\begin{array}{l}\text { Saturated } \\
\text { fatty acids }\end{array}$ & $\begin{array}{c}\text { Poly- } \\
\text { unsaturated } \\
\text { fatty acids }\end{array}$ \\
\hline & & \multicolumn{3}{|c|}{$\mathrm{m} \mu \mathrm{moles} / \mathrm{mg}$ protein } & & \multicolumn{2}{|c|}{$\mathrm{m} \mu \mathrm{moles} / \mathrm{mg}$ protein } \\
\hline 4 & - & - & - & - & 1 & 0.18 & 0.20 \\
\hline 7 & 2 & 0.09 & 0.87 & 0.11 & 2 & 0.19 & 0.84 \\
\hline 10 & - & - & - & - & 1 & 0.50 & 0.89 \\
\hline 15 & 2 & 0.43 & 1.38 & 0.49 & 2 & 3.63 & 1.89 \\
\hline 22 & 2 & 0.31 & 0.58 & 0.37 & 3 & 0.91 & 1.81 \\
\hline Adults & 6 & 0.30 & 0.49 & 0.37 & 11 & 0.87 & 1.99 \\
\hline
\end{tabular}

1 Values for incorporation represent means. The complete system contained the components as described under figure 1 . The reaction mixture was incubated $1 \mathrm{~h}$.

2 Number of experiments.

Table II. Products of fatty acid synthesis by 16 -day-old rat microsomal fraction

\begin{tabular}{|c|c|c|c|c|c|c|}
\hline \multirow{2}{*}{$\frac{\text { Time of incubation }}{\text { Garbon chain length }}$} & \multicolumn{2}{|c|}{$10 \min ^{1}$} & \multirow[t]{2}{*}{$\mathrm{RSA}^{2}$} & \multicolumn{2}{|c|}{$60 \min ^{1}$} & \multirow[t]{2}{*}{$\mathrm{RSA}^{2}$} \\
\hline & $\begin{array}{r}\text { Radioacti } \\
\text { Perce }\end{array}$ & $\begin{array}{l}\text { fty acids } \\
\text { f total }\end{array}$ & & \multicolumn{2}{|c|}{ Percentage of total } & \\
\hline $\mathrm{G}_{16: 0}$ & 6.9 & 28.8 & 0.23 & 8.4 & 24.0 & 0.35 \\
\hline $\begin{array}{l}\mathrm{C}_{18: 1} \\
\mathrm{C}_{18: 0}\end{array}$ & 16.0 & $\begin{array}{l}20.4 \\
20.3\end{array}$ & 0.39 & 27.2 & $\begin{array}{l}19.3 \\
24.2\end{array}$ & 0.62 \\
\hline $\mathrm{C}_{20: 4+20: 2}$ & 12.3 & 12.8 & 0.97 & 17.0 & 12.7 & 1.3 \\
\hline $\mathrm{C}_{22: 4+22: 6}$ & 31.1 & 16.6 & 1.9 & 14.6 & 17.9 & 0.87 \\
\hline $\mathrm{C}_{22: 0-24: 0^{3}}$ & 24.5 & 0.4 & 59.7 & 25.0 & 0.5 & 50.0 \\
\hline $\mathrm{C}_{24: 0}$ & 8.6 & trace & - & 7.1 & 1.4 & 5.0 \\
\hline
\end{tabular}

1 The complete system contained the components described under figure 1 . Incubation was carried out under nitrogen for 10 and $60 \mathrm{~min}$ at $38^{\circ}$.

${ }^{2}$ RSA (relative specific activity) the ratio of the percentage of total radioactivity collected to the percentage of total fatty acids in the particulate fraction.

3 These fractions were collected by gas-liquid chromatography between the two fatty acids listed, using a methyl silicone (SE-30) stationary system. 
15-16 days of age, the rate of labeling of polyunsaturated fatty acids did not change significantly from 15 days of age to maturity. As indicated by the incorporation of labeled precursor, synthesis of polyunsaturated fatty acids, particularly those of 22 carbon chain lengths $\left(\mathrm{C}_{22: 6}\right.$ and $\left.\mathrm{C}_{22: 4}\right)$, proceeded more rapidly during the first 10 min of incubation than did that of saturated fatty acids. This finding suggests that in the brain, desaturation and chain elongation proceed by a different synthetic mechanism.

While saturated fatty acids are found in all types of membranes, polyunsaturated fatty acids are found in large amounts in microsomes and mitochondria [4], but constitute $10 \%$ or less of total unsubstituted fatty acids of adult human myelin [6]. It can be assumed that one of the possible subcellular levels for the control of myelin synthesis in the developing brain may be localized to the chain elongation pathway responsible for the formation of the very long-chain saturated fatty acids.

\section{Summary}

Fatty acid biosynthesis in subcellular particles of the developing rat brain was studied. Total fatty acid synthesis was maximal at 15-16 days of age. Incorporation of malonyl-GoA into saturated fatty acids followed a similar time curve, while polyunsaturated fatty acid synthesis did not change significantly from 15 days of age to maturation.

These results support the concept that fatty acid chain elongation has a close time relation with myelination. The marked increase in the rate of saturated fatty acid synthesis by the microsomal fraction occurring at this time suggests that this system is involved in the synthesis of myelin fatty acids.

\section{References and Notes}

1. Aeberhard, E. and Menkes, J.H.: Biosynthesis of long chain fatty acids by subcellular particles of mature brain. J.biol. Chem. 243: 3834 (1968).

2. Bowyer, D.E.; Leat, W.M.F.; Howard, A.N. and Gresham, G.A.: The determination of the fatty acid composition of serum lipids separated by thin-layer chromatography; and a comparison with column chromatography. Biochim. biophys. Acta 70: 423 (1963).

3. Brady, R.O.; Bradley, R. M. and Trams, E.G.: Biosynthesis of fatty acids. I. Studies with enzymes obtained from liver. J. biol.Chem. 235: 3093 (1960).

4. Fleischer, S. and Rouser, G. : Lipids of subcellular particles. J.Amer. Oil Chem. Soc. 42: 588 (1965).
5. Folgh, J.; Lees, M. and Sloane-Stanley, G. H.: A simple method for the isolation and purification of total lipides from animal tissues. J. biol. Chem. 226: 497 (1957).

6. Gerstl, B.; Eng, L.F.; Hayman, R.B.; TavastJERNA, M.G. and BOND, P.R.: On the composition of human myelin. J. Neurochem. 14: 661 (1967).

7. Gibson, D. M.; Titchener, E.B. and WakiL, S. J.: Studies on the mechanism of fatty acid synthesis. $\mathrm{V}$. Bicarbonate requirement for the synthesis of long-chain fatty acids. Biochim. biophys. Acta 30: 376 (1958).

8. Goldfine, H. and Bloch, K.: On the origin of unsaturated fatty acids in Clostridia. J.biol. Ghem. 236: 2596 (1961)

9. Gornall, A.G.; Bardawill, G.J. and David, M. M.: Determination of serum proteins by means of the biuret reaction. J. biol. Chem. 177: 751 (1949).

10. Gray, E.G. and WhitTaker, V.P.: The isolation of nerve endings from brain: an electron-microscopic study of cell fragments derived by homogenization and centrifugation. J.Anat. 96: 79 (1962).

11. Harlan, W.R., Jr. and WakIL, S.J.: Synthesis of fatty acids in animal tissues. I. Incorporation of $\mathrm{C}^{14}$-acetyl coenzyme $\mathrm{A}$ into a variety of long chain fatty acids by subcellular particles. J. biol. Chem. 238: 3216 (1963).

12. Kishimoto, Y. and Radin, N.S.: Metabolism of brain glycolipid fatty acids. Lipids 1: 47 (1966).

13. Menkes, J.H.; Philippart, M. and Concone, M.C.: Concentration and fatty acid composition of cerebrosides and sulfatides in mature and immature human brain. J. Lipid Res. 7: 479 (1966).

14. MORRIs, L.J.: Separations of lipids by silver ion chromatography. J.Lipid Res. 7: 717 (1966).

15. Morrison, W.R. and Smith, L.M.: Preparation of fatty acid methyl esters and dimethyl acetals from lipids with boron fluoridemethanol. J. Lipid Res. 5: 600 (1964).

16. O'Brien, J.S.: Stability of the myelin membrane. Science 147: 1099 (1965).

17. SNyder, F. and Stephens, N.: Quantitative carbon-14 and tritium assay of thin-layer chromatography plates. Analyt. Biochem. 4: 128 (1962).

18. Ställberg-Stenhagen, S. and Svennerholm, L. : Fatty acid composition of human brain sphingomyelins: normal variation with age and changes during myelin disorders. J.Lipid Res. 6: 146 (1965).

19. WAKIL, S.J.: Mechanism of fatty acid synthesis. J. Lipid Res. 2: 1 (1961).

20. Fatty acids are denoted by chain length and number of double bonds, e.g., $C_{16: 0}$, palmitic acid;

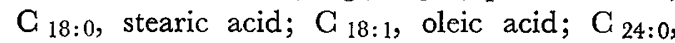
lignoceric acid; and $\mathrm{C}_{24: 1}$, nervonic acid. 
21. Obtained from New England Nuclear Corporation, Boston, Mass.

22. Purchased from Sigma Chemical Company, St. Louis, Mo.

23. Applied Science Laboratories, State College, $\mathrm{Pa}$.

24. Cab-O-Sil; PPO: 2-5-diphenyloxazole; and POPOP: 1,4-bis[(2-(5-phenyloxazolyl)]-benzene were obtained from Packard, La Grange, Ill.

25. Presented in part at the 28 th annual meeting of the
Society for Pediatric Research, Atlantic City, New Jersey, May 3-4, 1968.

26. Supported by Public Health Service Research Grant no. NB 06938 and by a grant from the United Cerebral Palsy Research and Educational Foundation.

27. Requests for reprints should be addressed to: Jorr H. MEnkes, M.D., Division of Neurology, UCLA School of Medicine, The Center for the Health Sciences, Los Angeles, California 90024 (USA). 